\title{
Antioxidant and proliferative activity of the fruit extract of Lycium chinense in regenerating liver after partial hepatectomy in rats.
}

\author{
Young Mo Ahn',2, Gyeong Seok Lee', Hyeon Gung Yang ${ }^{1}$, Eui Gil Jung ${ }^{1,3}$, Kook Il Han ${ }^{1,4}$, Man Deuk \\ Han', Wan Jong Kim ${ }^{1, *}$ \\ ${ }^{1}$ Department of Life Science and Biotechnology, College of Natural Sciences, Soonchunhyang University, Asan, Korea \\ ${ }^{2}$ Technical Development, BMIkorea, Jeju, Korea \\ ${ }^{3}$ Seoul Center, Korea Basic Science Institute, Seoul, Korea \\ ${ }^{4}$ Korean Collection for Type Cultures, Korea Research Institute of Bioscience and Biotechnology, Jeongeup, Korea
}

\begin{abstract}
Objective: This study was carried out to evaluate the antioxidant activity and effect of a hot water extract of Lycium chinense fruit (LFE) on liver regeneration induced by Partial Hepatectomy (PH) in rats.

Methods: Antioxidant activity of LFE was determined. Rats were divided into three groups; laparotomized (sham, $\mathbf{n = 1 5}$ ), $70 \%$ PH (control, $n=25$ ), and LFE-treated after PH (experimental, $n=35$ ). Starting 7 days before $\mathrm{PH}$, rats received DW or LFE $(500 \mathrm{mg} / \mathrm{kg}$ in DW) orally once a day until sacrifice. Rats were sacrificed on $\mathrm{d}$ 0.5, 1, 2, 3, and 7 after surgery. Liver regeneration ratio and Proliferating Cell Nuclear Antigen (PCNA) expression were determined through immunohistochemistry and western blotting.

Results: Final extraction yield of LFE was 36.0\%. LFE scavenged the DPPH and the ABTS radicals in a concentration-dependent manner. The $\mathrm{IC}_{50}$ of $\mathrm{LFE}$ on DPPH and ABTS antioxidant activity was 5.97 $\mathrm{mg} / \mathrm{ml}$ and $2.53 \mathrm{mg} / \mathrm{ml}$, respectively. The extent of liver regeneration seen in the experimental group

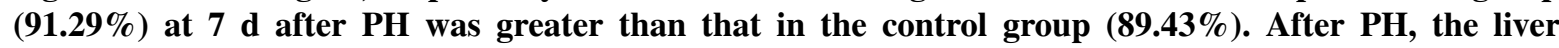
reconstruction process involving collapse, re-arrangement and re-modelling of hepatic tissue was observed to happen sooner in the experimental group. The number of PCNA-positive hepatocytes obviously increased in the experimental group. PCNA-positive hepatocyte ratio peaked at 2 and 3 d in the experimental and control groups, respectively.

Conclusions: Administration of LFE had beneficial effects on the regenerative capacity of remnant liver tissue after $70 \% \mathrm{PH}$ in rats, probably owing to its antioxidant and proliferative properties.
\end{abstract}

Keywords: Lycium chinense fruit, Antioxidant activity, Partial hepatectomy, Regenerating liver. Accepted on May 15, 2018

\section{Introduction}

Medicinal plants have been used throughout human history and make many chemical compounds that perform important biological functions. Lycium chinese originated in China is widely distributed in warm and subtropical regions of Japan, Korea, Southeastern Asia, and Europe. The dried ripe fruit has traditionally been used for anti-aging purposes. The fruit contains carotenoids, zeaxantin, betaine, choline, and ascorbic acid, and exerts various pharmacological effects, such as immune-promoting, anti-cancer, anti-diabetes, blood pressurereducing, and antioxidant effects [1-4].

A fascinating aspect of the liver is its remarkable capacity to regenerate itself after injury. Liver regeneration, which presumably evolved to protect animals in the wild from the catastrophic results of liver loss caused by toxins in food, has been a subject of curiosity for decades. The liver exhibits remarkable regrowth when it is damaged by physical stimuli such as Partial Hepatectomy (PH). $\mathrm{PH}$ is the strongest stimulator of hepatic regeneration. Hepatocytes can regenerate through a process of compensatory growth and return to their original number and a quiescent state $[5,6]$. Higgins and Anderson described a method of performing 2/3 $\mathrm{PH}$ in rats [7]. Since then, liver regeneration by $\mathrm{PH}$ has widely been used to investigate the response of the liver against injury and the regulatory mechanisms involved. Liver regeneration involves a successive, orchestrated response accompanied by sequential changes in gene expression, cytokine production, and morphological structuring [8-10]. 
Lycium chinense fruit (LF) has gained attention because of its possible benefits for treatment of $\mathrm{CCl}_{4}$-induced hepatotoxicity, hepatic fibrosis, and Alzheimer's disease $[11,12]$. Recently, the biological activity of Lycium chinense by which it exhibits hepatoprotective effects against oxidative stress or carbon tetrachloride $\left(\mathrm{CCl}_{4}\right)$-induced hepatotoxicity have been documented [4]. However, there are few reports on the proliferative effects of hot water extract of Lycium chinense fruits (LFE) on regeneration of liver following $\mathrm{PH}$ in rats.

In the present study, we investigated the effects of LFE with special attention to changes in cell proliferation and antioxidation during liver regeneration after $70 \% \mathrm{PH}$ in rats.

\section{Materials and Methods}

\section{Preparation of Lycium chinense fruit extract (LFE)}

LF were supplied by the Biomix Company (Cheongyang-gun, Chungcheongnam-do, Korea). The dried fruits were washed two times with water to remove dust, rinsed carefully with $\mathrm{DW}$, and then dried in a $60^{\circ} \mathrm{C}$ oven for $24 \mathrm{~h}$. Dried LF $(500 \mathrm{~g})$ were crushed and ground using a grinder and incubated three times in $600 \mathrm{ml} \mathrm{DW}$ at $90^{\circ} \mathrm{C}$ for $1 \mathrm{~h}$. The extract was filtered with Whatman filter paper (No. 2) and freeze-dried at $-50^{\circ} \mathrm{C}$ for $5 \mathrm{~d}$. Dried LFE powder was kept at $-20^{\circ} \mathrm{C}$ until use.

\section{Total polyphenol content}

Polyphenol content was measured by the ISO method with minor modifications. The principle is that the polyphenol content of the extract can be determined colorimetrically using Folin-Ciocalteu phenol reagent. Freeze-dried extract was diluted in the DW $(10 \mathrm{mg} / \mathrm{ml})$ and filtered. This extract was mixed with $10 \%$ folin-ciocalteau reagent (Sigma-Aldrich, United states) and 7.5\% sodium carbonate solution (SigmaAldrich, United states). The mixture was incubated in dark room at room temperature for $60 \mathrm{~min}$. The absorbance of the mixture was measured at a wavelength of $760 \mathrm{~nm}$ using a UVspectrophotometer (UV-1800, Shimadzu Co., Japan). Gallic acid (Sigma-Aldrich Co., United States) was used as a calibration standard. Total polyphenol content was expressed as milligram gallic acid equivalent per gram LFE (mg GAE/g).

\section{DPPH radical scavenging activity}

The free radical scavenging activity of the LFE was measured by the 1, 1-diphenyl-2-picryl-hydrazil (DPPH) method with slight modifications [13]. Briefly, a $0.2 \mathrm{mM}$ solution of DPPH in methanol was prepared and $180 \mu \mathrm{l}$ of this solution was added to $20 \mu \mathrm{l}$ of the extract at different concentrations $(0.25$, $0.5,1,2$, and $4 \mathrm{mg} / \mathrm{ml})$. The mixture was shaken vigorously and allowed to stand at room temperature for $20 \mathrm{~min}$. Then, the absorbance was measured at $517 \mathrm{~nm}$ using a microplate reader (Epoch, BioTek Instruments Inc., United States). The DPPH radical scavenging capability of LFE was calculated using the following equation: DPPH scavenging effect $(\%)=\left(\left(\mathrm{A}_{0^{-}}\right.\right.$ $\left.\left.A_{1}\right) / A_{0}\right) \times 100(\%)$, where $A_{0}$ is the absorbance of the control reaction and $A_{1}$ is the absorbance in the presence of the extract samples or the standard.

\section{ABTS radical scavenging activity}

To assess antioxidant activity, 2, 2-azinobis-(3-ethylbenzothiazoline-6-sulphonate) (ABTS) radical scavenging activity was determined as described below [14]. ABTS was dissolved in water at a concentration of $7 \mathrm{mM}$. The ABTS radical cation was produced by reacting ABTS stock solution with $2.4 \mathrm{mM}$ potassium persulfate and allowing the mixture to stand in the dark for $12 \mathrm{~h}$ until use. This solution was added to $20 \mu \mathrm{l}$ of the extract at different concentrations $(0.25,0.5,1,2$, and $4 \mathrm{mg} /$ $\mathrm{ml})$. The percentage inhibition of absorbance at $734 \mathrm{~nm}$ was calculated and plotted as a function of the concentration of antioxidants, using Trolox for standard reference data.

\section{Experimental animals and $L F E$ administration}

All animal experiments were approved by the University of Soonchunhyang Institutional Animal Care and Usage Committee (permission No.: SCH15-0026). Male SpragueDawley rats $(150 \pm 10 \mathrm{~g})$ were purchased from KoaTech Co. (Korea). They were fed a diet of standard rat chow, given free access to tap water, and kept in a temperature- and humiditycontrolled animal laboratory. The 75 rats were randomly divided into 3 groups: (1) laparotomized-only group (sham, $\mathrm{n}=15$ ); (2) 70\% PH-only group (control, $\mathrm{n}=25$ ); and (3) LFEtreated group after $70 \% \mathrm{PH}$ (experimental group, $\mathrm{n}=35$ ). Starting 7 days before $\mathrm{PH}$, rats received DW or LFE (500 $\mathrm{mg} / \mathrm{kg}$ in DW) orally once a day until sacrifice. Rats in each group were sacrificed on d $0.5,1,2,3$, and 7 after surgery.

\section{0\% partial hepatectomy}

Under $2 \%$ isoflurane anaesthesia, $70 \% \mathrm{PH}$ involving median and left lateral lobectomy was performed according to the procedure of Higgins [7].

\section{Determination of the liver regeneration ratio}

The ration of liver regeneration at $0.5,1,2,3$, and $7 \mathrm{~d}$ after $\mathrm{PH}$ was calculated according to the following equation: ratio of liver regeneration $(\%)=$ regenerated remnant liver $(\mathrm{g}) \times 100$ $(\%)$ /estimated whole liver $(\mathrm{g})$, where estimated whole liver $(\mathrm{g})=$ resected liver $(\mathrm{g}) \times 100 / 70$.

\section{Light microscopic immunohistochemistry for determination of PCNA}

For light microscopy, liver tissues were rapidly removed from sacrificed animal, fixed in $10 \%$ formalin, and embedded in paraffin by routine procedures. Sections ( $5 \mu \mathrm{m}$ thick) were stained with Hematoxylin and Eosin (H-E). For immunohistochemistry for PCNA, the paraffin-embedded sections were hydrated and incubated in $10 \mathrm{mM}$ sodium citrate buffer ( $\mathrm{pH} 6.0$ ) at $95^{\circ} \mathrm{C}$ for $20 \mathrm{~min}$ to retrieve antigenicity. Sections were treated with $3 \%$ hydrogen peroxide diluted in $10 \%$ methanol for $15 \mathrm{~min}$ and blocked by $10 \%$ bovine serum albumin for $1 \mathrm{hr}$. The sections were incubated with primary 
antibody (1:5,000, PCNA mouse monoclonal antibody; Abcam Co., United Kingdom) at room temperature for $1 \mathrm{~h}$. After rinsing in buffer, samples were treated with biotinylated secondary antibody (DAKO, United States) and incubated in streptavidin-HRP (DAKO, United States) for $15 \mathrm{~min}$. The samples were then stained with DAB (3, 3'-diaminobenzidine). All steps were carried out in a humidified chamber. Observation was conducted by light microscopy at $200 \mathrm{X}$ magnification and PCNA-positive hepatocytes were counted in a double-blind test.

\section{Western blotting for PCNA}

Tissues were homogenized and lysed with protein extraction solution (PRO-PREPTM, iNtRON, Korea). After centrifugation $(13,000 \mathrm{rpm})$ at $4^{\circ} \mathrm{C}$ for $20 \mathrm{~min}$, the supernatant was collected and stored at $-80^{\circ} \mathrm{C}$ until use. Protein concentration was measured at $540 \mathrm{~nm}$ using the BCA protein assay commercial kit (Thermo Co., United States). For SDS-PAGE, $30 \mu \mathrm{g}$ protein/lane was loaded onto a 10\% SDS-PAGE and was then transferred onto a PVDF membrane (Bio-Rad Lab Inc., United States) at $2.5 \mathrm{~A}$ for $10 \mathrm{~min}$. Blocking was carried out in $5 \%$ skim milk for $1 \mathrm{~h}$ and then the membranes were incubated with the primary antibody $(1: 5,000$, PCNA mouse monoclonal antibody; Abcam Co., United Kingdom) at $4^{\circ} \mathrm{C}$ overnight. Monoclonal mouse anti- $\beta$-actin (1:20,000, Sigma-Aldrich Co., United States) was used as a control. The membrane was incubated with secondary antibody $(1: 2,000$, rabbit anti-mouse IgG-HRP; Santa Cruz Co., United States) at room temperature for $1 \mathrm{~h}$. Protein signals were detected by enhanced chemiluminescence (Advansta Co., United States) and analysed with a chemiluminescent imaging system (Syngene Co., United States).

\section{Statistical analysis}

All experimental data are expressed as mean $\pm \mathrm{SD}$. Using the SPSS, the Student's t-test was applied to determine the significance of differences between the control and experimental groups. $\mathrm{P}<0.05$ was regarded as significant.

\section{Results}

\section{Determination of total polyphenol content}

The final yield by hot water extraction of LF was $36.0 \%$. The total polyphenol content, including anthocyan and flavonoids, was $1.47 \mathrm{mg} \mathrm{GAE} / \mathrm{g}$ and the betaine content was $1.4 \%$ (Table 1).

\section{$D P P H$ and $A B T S$ free radical scavenging activity of LFE}

The DPPH and ABTS radical scavenging activity was investigated using calculation of $\mathrm{IC}_{50}$ (inhibitory concentration; concentration needed to inhibit $50 \%$ of radical) (Table 2). LFE scavenged DPPH radical in a concentrationdependent manner: $0.37 \%$ at $0.25 \mathrm{mg} / \mathrm{ml}, 1.67 \%$ at $0.5 \mathrm{mg} / \mathrm{ml}$, $5.25 \%$ at $1 \mathrm{mg} / \mathrm{ml}, 12.26 \%$ at $2 \mathrm{mg} / \mathrm{ml}$ and $35.11 \%$ at $4 \mathrm{mg} / \mathrm{ml}$.
$\mathrm{IC}_{50}$ of LFE was $5.97 \mathrm{mg} / \mathrm{ml}$ and that of the positive control, Butylated Hydroxyanisole (BHA), was $2.13 \mu \mathrm{g} / \mathrm{ml}$ (Figure 1a). Also, LFE scavenged ABTS radical in a concentrationdependent manner: $9.02 \%$ at $0.25 \mathrm{mg} / \mathrm{ml}, 17.07 \%$ at 0.5 $\mathrm{mg} / \mathrm{ml}, 24.40 \%$ at $1 \mathrm{mg} / \mathrm{ml}, 38.89 \%$ at $2 \mathrm{mg} / \mathrm{ml}$, and $76.01 \%$ at $4 \mathrm{mg} / \mathrm{ml}$. The $\mathrm{IC}_{50}$ of LFE was $2.53 \mathrm{mg} / \mathrm{ml}$, and that of the positive control, Trolox, was $1.47 \mu \mathrm{g} / \mathrm{ml}$ (Figure 1b).
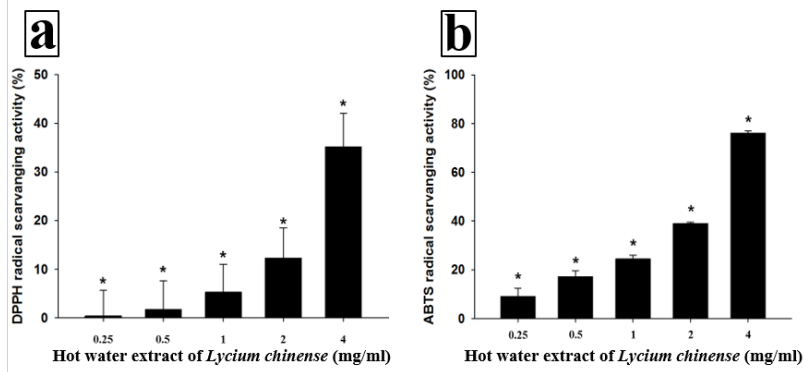

Figure 1. DPPH (a) and ABTS (b) free radical scavenging activities of hot water extract from Lycium chinense fruits. The values are significantly lower free radical scavenging activity in LFE compared with the BHA or Trolox as control. ( $\left.{ }^{*}<<0.01\right)$ DPPH: 2, 2-diphenyl-1picrylhydrazyl, ABTS: 2, 2-azinobis-(3-ethylbenzo-thiazoline-6sulphonate), BHA: Butylated Hydroxyl Anisole; Trolox: 6-hydroxy-2, 5, 7, 8-tetramethyl-chroman-2-carboxylic acid.

\section{Liver regeneration}

The wet weight of the remnant liver in the $70 \% \mathrm{PH}$ group increased rapidly, reaching about $90 \%$ of the original liver weight on $d 7$ of surgery (Table 3 ). The increase seen in the experimental groups was faster than that in the control group, but the difference was not statistically significant (Figure 2).

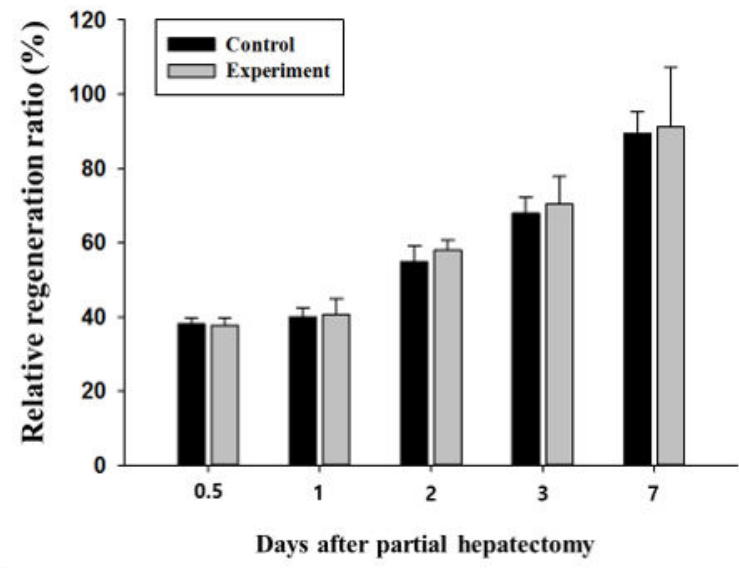

Figure 2. Relative regeneration ratio of remnant liver partial hepatectomy. The result showed rapid liver regeneration in the experimental group compared with the control group from $2 \mathrm{~d}$ to $7 \mathrm{~d}$ after $70 \%$ PH. However, there was no statistical significance.

\section{Changes of body weight of animal}

Before and after $7 \mathrm{~d} \mathrm{PH}$, we measured and recorded body weight of rats. Weights of all groups are gradually increased with the course of time. Weights of control and experimental groups showed similar tendency that gradually increased until 
operated day and slightly decreased for a few days due to recovery after surgery and then increased again (data not shown).

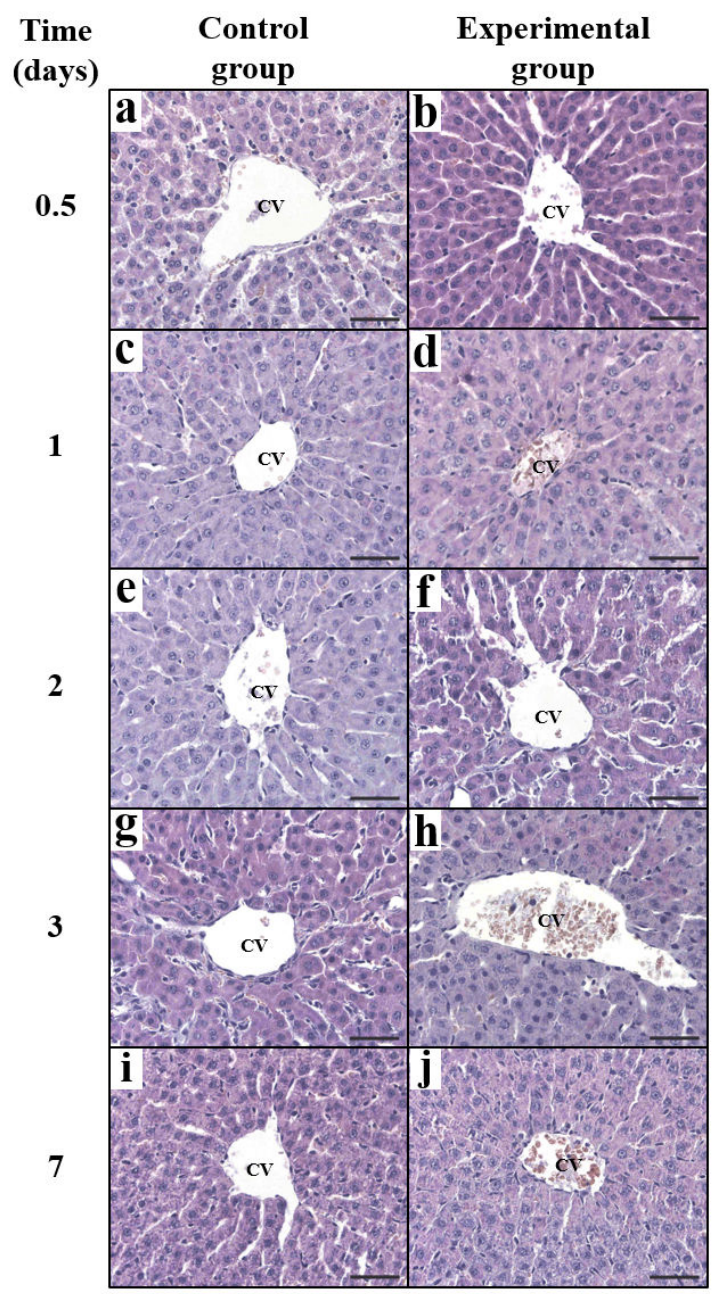

Figure 3. Light micrographs of regenerating rat liver after $70 \%$ partial hepatectomy. Histological structure shows similar on remnant liver tissues of the control and experimental group at $0.5 d$ ( $a$ and $b$ ) and $1 d$ ( $c$ and $d$ ) after $P H$. Whereas, in the experimental group, collapse of hepatic plates shows noticeable at $2 d(e)$ compared with the control group (f). The dividing features of hepatocytes are observed in control $(g)$ and experimental (h) group at $3 \mathrm{~d}$ after $70 \%$ PH. But, proliferation of hepatocytes after collapse is faster in experimental group compared with the control group. At $7 d$, both control (i) and experimental (j) group are similarly shown in histological structure compared with normal liver tissue. CV: Central Vein; HE stain, scale bar: $50 \mu m$.

\section{Light microscopy and immunohistochemistry for PCNA}

As observed by light microscopy, liver regeneration induced by PH seemed to involve the proliferation of various hepatic cells, including parenchymal cells and Kupffer cells, in remnant liver. Histologically, the disintegration $(1 \mathrm{~d}$ after $\mathrm{PH})$ and remodelling ( $3 \mathrm{~d}$ after $\mathrm{PH})$ of hepatic plates and the increase of sinusoids ( $3 \mathrm{~d}$ after $\mathrm{PH})$ were evident. These regenerative processes, which included active mitotic features, occurred earlier in the experimental (LFE treated) groups. On d 7 after $\mathrm{PH}$, the architecture of the hepatic lobes was typically rearranged (Figure 3). The peripheral region of the central vein in liver lobules was mainly observed to compare the structural changes that occurred during regeneration between the two groups. Briefly, LFE administration could accelerate liver regenerating induced by $\mathrm{PH}$ in rats.

To determine whether LFE administration could promote the proliferation of hepatic cells in regenerating liver, immunohistochemistry for PCNA was performed (Figure 4). The negative control (without treatment with primary antiPCNA) showed no positivity for reaction products. The intensity of the positive reaction and the number of positive hepatocytes were compared between groups in a time course study. PCNA expression in liver cells started to increase on $\mathrm{d} 1$ after $\mathrm{PH}$ and peaked on $\mathrm{d} 3$ after $\mathrm{PH}$. PCNA expression in the experimental group was present earlier and was stronger than that in the control group. Similarly, the number of PCNApositive hepatocytes in the experimental group was predominant in the early days (Table 4). LFE administration promoted PCNA expression in proliferating hepatocytes during liver regeneration induced by $70 \% \mathrm{PH}$.

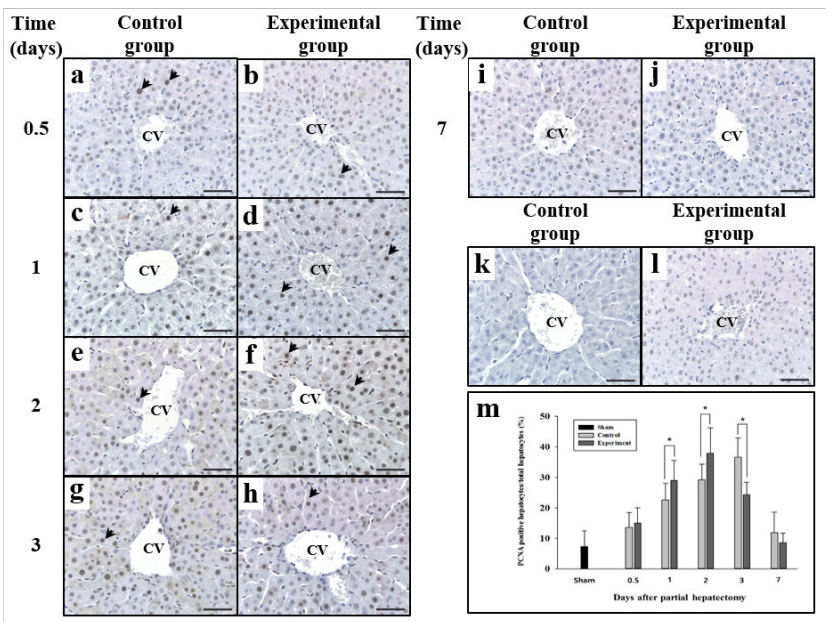

Figure 4. Immunohistochemical staining for Proliferating Cell Nuclear Antigen (PCNA) on regenerating liver tissue after $70 \%$ partial hepatectomy. At $0.5 \mathrm{~d}$ after $70 \%$ PH, PCNA immunoreactivity of control (a) and experimental (b) group are not different each other. But, it shows increased more PCNA positive hepatocyte in experimental group (d) compared with the control group (c) at $1 \mathrm{~d}$. At $2 \mathrm{~d}$ after $70 \% \mathrm{PH}, \mathrm{PCNA}$ positive hepatocytes significantly increased in liver tissue in experimental group (e) compared with control group (f). But, it is higher in the control group (g) than experimental group (h) at $3 d$. Then, both groups (I and j) are similar each other at $7 d$. ( $k$ ) is negative control, (l) is sham control and $(m)$ is labeling index for PCNA positive hepatocyte in the regenerating rat liver tissue. The experimental group rapidly increased PCNA positive hepatocytes more than control group until $2 d .\left(^{*} P<0.05\right.$ compared with the control group) CV: Central Vein, arrow: PCNA positive hepatocyte, PH: Partial Hepatectomy, scale bar: $50 \mu \mathrm{m}$.

\section{Western blotting for PCNA}

The Western blotting analysis of PCNA expression produced results similar to those seen via immunohistochemical staining 
(Figure 5). PCNA protein demonstrated an obvious increase until d 2 after $\mathrm{PH}$ and decreased thereafter in both groups. The protein levels in the experimental groups were higher in the first half of the experiment, but were lower in the second half than were those in the control group (Table 5). Briefly, LFE administration promoted PCNA expression during liver regeneration induced by $\mathrm{PH}$ in rats.
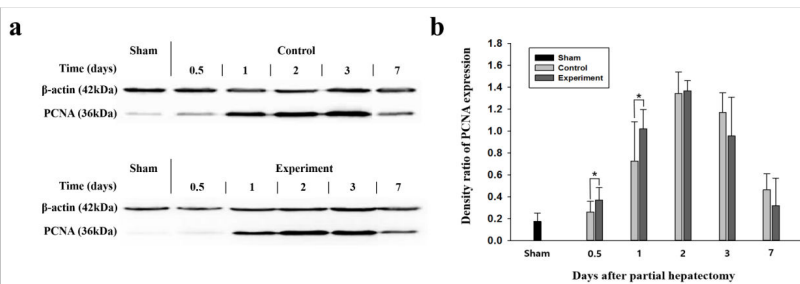

Figure 5. Western blot of PCNA protein expression in remnant liver tissue after partial hepatectomy. The result of western blot for PCNA (a) and relative expression of PCNA (b) in comparison with $\beta$-actin expression. PCNA protein expression was revised with the $\beta$-actin protein expression. PCNA protein expression increased in control and experimental groups until $2 d$ after PH. But, it significantly increased in the experimental group compared with control group at 0.5 and 1 d. Then, it is decreased until 7 in both groups. $\left({ }^{*} P<0.05\right)$.

Table 1. Total polyphenolic and betaine content of hot water extract from Lycium chinense fruits.

\begin{tabular}{llll}
\hline Sample & Extraction yield (\%) & TPC (mg GAE/g) & Betaine (\%) \\
\hline LFE & 36 & $1.47 \pm 0.22$ & 1.4 \\
\hline
\end{tabular}

Table 2. Antioxidant capacity of hot water extracts from Lycium chinense fruits.

\begin{tabular}{lllll}
\hline Sample & DPPH $\left(\mathbf{I C}_{50}\right)$ & ABTS $\left(\mathbf{I C}_{50}\right)$ & & \\
\hline LFE & $5.97 \pm 1.09(\mathrm{mg} / \mathrm{ml})$ & $2.53 \pm 0.17(\mathrm{mg} / \mathrm{ml})$ & \\
\hline $\mathrm{BHA}^{*}$ & $2.13 \pm 0.08(\mu \mathrm{g} / \mathrm{ml})$ & - & & \\
\hline Trolox & - & $1.47 \pm 0.02(\mu \mathrm{g} / \mathrm{ml})$ & & \\
\hline $\begin{array}{l}\text { *BHA: } \\
\text { tetramethylchroman-2-carboxylic acid. }\end{array}$ & & & \\
\hline
\end{tabular}

Table 3. Liver regeneration ratio (\%) after hepatectomy.

\begin{tabular}{lll}
\hline Time (d) & \multicolumn{2}{l}{ Groups } \\
\cline { 2 - 3 } & Control & Experiment \\
\hline 0.5 & $38.03 \pm 1.57$ & $37.66 \pm 2.01$ \\
\hline 1 & $40.02 \pm 2.37$ & $40.70 \pm 4.20$ \\
\hline 2 & $54.93 \pm 4.21$ & $58.01 \pm 2.81$ \\
\hline 3 & $67.86 \pm 4.39$ & $70.39 \pm 7.51$ \\
\hline 7 & $89.43 \pm 5.76$ & $91.29 \pm 15.98$ \\
\hline
\end{tabular}

Table 4. Proliferating Cell Nuclear Antigen (PCNA) positive hepatocytes ratio (\%) on liver tissue.

\begin{tabular}{llll}
\hline Time (d) & Sham & Control & Experiment \\
\hline
\end{tabular}

\begin{tabular}{llll}
\hline 0 & $7.29 \pm 5.2408$ & - & - \\
\hline 0.5 & - & $13.54 \pm 4.88$ & $14.92 \pm 5.02$ \\
\hline 1 & - & $22.55 \pm 5.51$ & $28.94 \pm 6.60^{*}$ \\
\hline 2 & - & $29.12 \pm 5.18$ & $37.78 \pm 8.55^{*}$ \\
\hline 3 & - & $36.64 \pm 6.30$ & $24.27 \pm 4.13^{*}$ \\
\hline 7 & - & $11.86 \pm 6.62$ & $8.52 \pm 3.17$ \\
\hline
\end{tabular}

Table 5. Evaluation of PCNA protein expression in regenerating rat liver after partial hepatectomy using Western blot.

\begin{tabular}{llll}
\hline Time (d) & Sham & Control & Experiment \\
\hline 0 & $0.17 \pm 0.08$ & - & - \\
\hline 0.5 & - & $0.26 \pm 0.10$ & $0.37 \pm 0.11$ \\
\hline 1 & - & $0.73 \pm 0.36$ & $1.02 \pm 0.18$ \\
\hline 2 & - & $1.34 \pm 0.19$ & $1.37 \pm 0.09$ \\
\hline 3 & - & $1.17 \pm 0.18$ & $0.95 \pm 0.15$ \\
\hline 7 & - & $0.46 \pm 0.15$ & $0.32 \pm 0.25$ \\
\hline
\end{tabular}

Each value was expressed as relative densities compared with $\beta$-actin expression.

\section{Discussion}

Lycium chinense Miller is widely distributed in warm and subtropical regions of Japan, Korea, Southeastern Asia and Europe. Its fruit (LF) has traditionally been used for anti-aging and hepatoprotective purposes. LF was consumed as a health food supplement and a medicinal herb in China, Korea, and other countries. This study was carried out to determine the antioxidant activity and the effects of a hot water extract of Lycium chinense fruits (LFE) on liver regeneration after Partial Hepatectomy $(\mathrm{PH})$ in rats.

Medicinal plants have been extensively studied for their antioxidant activity in recent years. Antioxidants from various plants have been studied to develop natural formulations for many applications [15]. Flavonoids are known to be phenolic antioxidants, which play an important role in the oxidation process because they are preferentially oxidized by an attacking radical [16]. In vitro studies have reported that LF has a protective effect against hepatotoxicity induced by oxidative stress via scavenging reactive oxygen species and enhancing antioxidant enzyme activity in cells and has hepatoprotective activity against $\mathrm{CCl}_{4}$-induced liver [4].

The total polyphenolic contents of the LFE are listed in Table 1. In general, extraction yield increased with increasing water content in ethanol, acetone, and methanol systems. This may be caused by the combination of organic solvent and water facilitating the extraction of all compounds that are soluble in both water and organic solvents. Therefore, it seems that the LFE contained more nonphenolic compounds. To determine the antioxidant effects of LFE, DPPH and ABTS free radical scavenging activities were tested; $\mathrm{IC}_{50}$ (inhibitory concentration) of them were $5.97 \mathrm{mg} / \mathrm{ml}$ and $2.53 \mathrm{mg} / \mathrm{ml}$, 
respectively, so the extract showed efficient antioxidant capability. The antioxidant activity of LFE in our results might be related to the presence of phenolic compounds such as myricetin, quercetin and kaempferol. Because LF has many phenolic compounds and they showed free radical scavenging and stimulating antioxidative enzymes [1,3,17]. Similarly, Lycium barbarum also has phenolic compound and antioxidative glycosidic constituents $[18,19]$. LFE may be useful for preventing hepatic damage induced not only by $\mathrm{PH}$ but also by inflammation.

We also determined whether LFE affects cellular proliferation during liver regeneration induced by $\mathrm{PH}$. The unusual regenerative properties of the liver evolved for adaptive purposes, and $\mathrm{PH}$ is the most often used stimulus to study liver regeneration; it is preferred over other methods that use hepatic toxins because it does not cause tissue injury and inflammation, and the initiation of the regenerative stimulus is precisely defined. Liver regeneration seemed to start immediately after $\mathrm{PH}$ and involved the proliferation of various hepatic cells, including parenchymal cells and Kupffer cells, in the remnant liver [20].

We tested the changes in body weight and liver function (activities of AST, ALT and ALP, and total cholesterol) of all animals at the time of sacrifice (data not shown), and found few differences between the control and experimental groups. This indicates that LFE has no deleterious effects on metabolism in rats. Before and after $7 \mathrm{~d}$ for $\mathrm{PH}$, body weights are gradually increased in all group and animals normally grow up during the experiment. Weights of control and experimental group showed similar tendency that gradually increased until hepatectomized day and slightly decreased for a few days due to recovery after surgery and then increased again. It could indicate that LFE has no deleterious or adverse effects.

The weight increase in remnant lobes in the experimental groups occurred faster than it did in the control group; however, to confirm these findings, further experimentation is needed. LFE administration accelerated the disintegration and re-modelling of hepatic plates and the increase of sinusoids.

PCNA is a nuclear protein which serves as a cofactor for DNA polymerase- $\delta$ and is involved in the coordination of cell cycle progression and DNA replication [21,22]. To determine whether LFE administration could promote the proliferation of hepatic cells in regenerating liver, immunohistochemistry and Western blotting for PCNA were performed. PCNA expression in liver cells started to increase on $\mathrm{d} 1$ after $\mathrm{PH}$ and peaked on d 3 after PH. PCNA expression in the experimental group occurred earlier and was stronger than that in the control group. Western blotting and immunohistochemistry produced consistent results for PCNA expression. Briefly, LFE administration promoted PCNA expression during liver regeneration induced by $\mathrm{PH}$ in rats. Recently, it was reported also proliferative effects in rat renal progenitor cells [23]. Cumulative effects of proliferative, anti-oxidative and cytoprotective activities of LFE can accelerate liver regeneration.
In the present study, we investigated the effects of hot water extract of LFE on liver regeneration induced by $70 \% \mathrm{PH}$ in rat model. We found that LFE can alleviate oxidative stress and promote PCNA expression of hepatic cell during the regeneration. It is suggested that the oral administration of LFE may have beneficial effects on the regenerative capacity of remnant liver tissue after partial hepatectomy in rats. Although, much has been revealed about liver regeneration and the substances that promote it, more must be identified and exploited for clinical applications.

\section{Acknowledgements}

This work was supported in part by the Soonchunhyang University Research Fund.

\section{References}

1. Lin CC, Chuang SC, Lin JM and Yang JJ. Evaluation of the antiinflammatory hepatoprotective and antioxidant of Lycium chinense from Taiwan. Phytomedicine 1997; 4: 213-220.

2. Kim OK. Antidiabetic and antioxidative effect of Lycii fructus in streptozotocin-induced diabetic rats. Kor J Pharmacongn 2009; 40: 128-136.

3. Zhang R, Kang KA, Piao MJ, Kim KC, Kim AD, Chae SW, Park JS, Youn UJ, Hyun JW. Cytoprotective effect of the fruits of Lycium chinense Miller against oxidative stress-induced hepatotoxicity. J Ethopharmacol 2010; 130: 299-306.

4. Ahn MJ, Park JS, Chae SW, Kim SJ, Moon CJ, Hyun JW, Shin TK. Hepatoprotective effects of Lycium chinense Miller fruit and its constituent betaine in CCl4-induced hepatic damage in rats. Acta Histochem 2014; 116: 1104-1112.

5. Mangnall D, Bird NC, Majeed AW. The molecular physiology of liver regeneration following partial hepatectomy. Liver Int 2003; 23: 124-138.

6. Michalopoulos GK. Liver regeneration. J Cell Physiol 2007; 213: 286-300.

7. Higgins GM, Anderson RM. Restoration of the liver of the white rat following partial surgical removal. Arch Pathol 1931; 12: 186-202.

8. Michalopoulos GK, DeFrances MC. Liver regeneration. Science 1997; 276: 60-66.

9. Tao Y, Wang M, Chen E, Tang H. Liver regeneration: Analysis of the main relevant signaling molecules. Mediators Inflamm 2017; 2017: 4256352.

10. Michalopoulos GK, Khan Z. Liver regeneration, growth factors, and amphiregulin. Gastroenterology 2005; 128: 503-506.

11. Ye M, Moon J, Yang J, Lim HH, Hong SB, Shim I, Bae H. The standardized Lycium chinense fruit extract protects against Alzheimers disease in $3 \times \mathrm{Tg}-\mathrm{AD}$ mice. $\mathrm{J}$ Ethnopharmacol 2015; 172: 85-90.

12. Ha KT, Yoon SJ, Choi DY, Kim DW, Kim JK, Kim CH. Protective effect of Lycium chinense fruit on carbol 


\section{hepatectomy in rats}

tetrachloride-induced hepatotoxicity. J Ethnopharmacol 2005; 96: 529-535.

13. Do QD, Angkawijaya AE, TranNguyen PL, Huynh LH, Soetaredjo FE, Ismadji S, Ju YH. Effect of extraction solvent on total phenol content, total flavonoid content, and antioxidant activity of Limnophila aromatica. J food Drug Anal 2014; 22: 296-302.

14. Re R, Pellegrini N, Proteggente A, Pannala A, Yang M, Rice-Evans C. Antioxidant activity applying an improved ABTS radical cation decolorization assay. Free Radic Biol Med 1999; 26: 1231-1237.

15. Bhawna S, Kumar SU. Hepatoprotective activity of some indigenous plants. Int $\mathrm{J}$ Pharmatech Res 2009; 1: 1330-1334.

16. Foti MC. Antioxidant properties of phenols. J Pharm Pharmacol 2007; 59: 1673-1685.

17. Kim L, FrancisC, Ken N. Identification and quantification of antioxidants in Fructus lycii. Food Chem 2007; 105: 353-363.

18. Ming M, Guanhua L, Zhanhi Y, Guang C, Xuan Z. Effect of the Lycium barbarum polysaccharides administration on blood lipid metabolism and oxidative stress of mice fed high-fat diet in vivo. Food Chem 2009; 113: 872-877.

19. Chung IM, Ali M, Nagella P, Ahmad A. New glycosidic constituents from fruits of Lycium chenense and their antioxidant activieies. Arabian Journal of Chemistry 2015; 8: 803-911.
20. Andersen KJ, Knudsen AR, Kannerup AS, Sasanuma H, Nyengaard JR, HamiltonDutoit S, Erlandsen EJ, J $\varphi$ rgensen B, Mortensen FV. The natural history of liver regeneration in rats: Description of an animal model for liver regeneration studies. Int J Surg 2013; 11: 903-908.

21. Tanno M, Taguchi T. Proliferating cell nuclear antigen in normal and regenerating rat liver. Exp Mol Pathol 1999; 67: 192-200.

22. Mighell A. Proliferating cell nuclear antigen: Oral Surg Oral Med Oral Pathol Oral Radiol Endod 1995; 80: 3-4.

23. Wang H, Lau BW, Wang N, Wang S, Lu Q, Chang RC, So $\mathrm{K}$. Lycium barbarum polysaccharides promotes in vivo proliferation of adult rat retinal progenitor cells. Neural Regen Res 2015; 10: 1976-1981.

\section{"Correspondence to}

Wan Jong Kim

Department of Life Science and Biotechnology

College of Natural Sciences

Soonchunhyang University

Korea 